\title{
Resistance of MLL-AFF1-positive acute lymphoblastic leukemia to tumor necrosis factor-alpha is mediated by $\mathrm{S100A6}$ upregulation
}

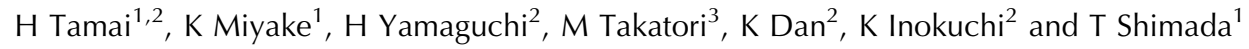 \\ ${ }^{1}$ Department of Biochemistry and Molecular Biology, Division of Gene Therapy Research Center for Advanced Medical \\ Technology, Nippon Medical School, Tokyo, Japan; ${ }^{2}$ Department of Hematology, Nippon Medical School, Tokyo, Japan \\ and ${ }^{3}$ Research Center for Life Science, Nippon Medical School, Tokyo, Japan
}

\begin{abstract}
Mixed-lineage leukemia (MLL)-AFF1 (MLL-AF4)-positive acute lymphoblastic leukemia (ALL) is associated with poor prognosis, even after allogeneic hematopoietic stem cell transplantation (allo-HSCT). The resistance to graft-versus-leukemia (GVL) effects may be responsible for the poor effect of alloHSCT on MLL-AFF1-positive ALL. Cytotoxic effector mechanisms mediated by tumor necrosis factor-alpha (TNF- $\alpha$ ) was reported to contribute to the GVL effect. We showed that MLL-AFF1-positive ALL cell lines are resistant to TNF- $\alpha$. To examine the mechanism of resistance to TNF- $\alpha$ of MLL-AFF1-positive leukemia, we focused on S100A6 as a possible factor. Upregulation of S100A6 expression and inhibition of the p53-caspase 8-caspase 3 pathway were observed only in MLL-AFF1-positive ALL cell lines in the presence of TNF- $\alpha$. The effect of S100A6 on resistance to TNF- $\alpha$ by inhibition of the p53-caspase 8-caspase 3 pathway of $M L L-A F F 1$-positive ALL cell lines were also confirmed by analysis using small interfering RNA against S100A6. This pathway was also confirmed in previously established MLL-AFF1 transgenic mice. These results suggest that MLL-AFF1-positive ALL escapes from TNF- $\alpha$-mediated apoptosis by upregulation of S100A6 expression, followed by interfering with p53-caspase 8 -caspase 3 pathway. These results suggest that S100A6 may be a promising therapeutic target for MLL-AFF1-positive ALL in combination with allo-HSCT.
\end{abstract}

Blood Cancer Journal (2011) 1, e38; doi:10.1038/bcj.2011.37;

published online 4 November 2011

Keywords: mixed lineage leukemia; S100A6; TNF- $\alpha$; GVL effect; $M L L-A F F 1$

\section{Introduction}

Rearrangements of the mixed-lineage leukemia $(M L L)$ gene located at $11 \mathrm{q} 23$ are common chromosomal abnormalities associated with acute leukemia, especially infant leukemia and secondary leukemia, following treatment with DNA topoisomerase II inhibitors. In addition, $11 \mathrm{q} 23 / \mathrm{MLL}$ abnormalities are now widely recognized as important prognostic factors in acute leukemia. Over 70 chromosomal partners of $11 q 23$ have been identified to date, at least 50 of which have been cloned and characterized at the molecular level. ${ }^{1}$ The prognosis of leukemia patients with $M L L$ rearrangement varies widely, depending upon the partner gene, leukemia cell lineage, age of the patient and the treatment administered. ${ }^{2}$ The most prevalent $M L L$ rearrangement

Correspondence: Dr H Tamai, Department of Biochemistry and Molecular Biology, Division of Gene Therapy Research Center for Advanced Medical Technology, Nippon Medical School, Tokyo 113-8602, Japan.

E-mail: s6056@nms.ac.jp

Received 23 June 2011; revised 1 August 2011; accepted 10 August 2011 in acute lymphoblastic leukemia (ALL) generates the MLL-AFF1 (MLL/AF4) fusion gene due to a $t(4 ; 11)(\mathrm{q} 21 ; \mathrm{q} 23)$ chromosomal translocation. Despite recent improvements in the overall treatment outcome for ALL patients, MLL-AFF1-positive ALL is still associated with a poor prognosis, one reason for which is the ineffectiveness of allogeneic hematopoietic stem cell transplantation (allo-HSCT). ${ }^{2}$ Considering this clinical course, MLL-AFF1-positive ALL may acquire some mechanisms to escape from graft-versus-leukemia (GVL) effects after allo-HSCT. Donor $\mathrm{CD}^{+}{ }^{+}, \mathrm{CD}^{+}{ }^{+}$and natural killer cells have been reported to mediate the GVL effect. ${ }^{3}$ Although the mechanism underlying the GVL effect mediated by these cells is not completely understood, cytotoxic effector mechanisms mediated by tumor necrosis factoralpha $(\mathrm{TNF}-\alpha)$ were reported to be one of the most important factors associated with the GVL effect. ${ }^{3}$

S100A6 is a $10.5-\mathrm{kDa}$ calcium $\left(\mathrm{Ca}^{2+}\right)$-binding protein that belongs to the S100 protein family and contains two EF-hand motifs responsible for binding of $\mathrm{Ca}^{2+} \cdot{ }^{4}$ Binding of $\mathrm{Ca}^{2+}$ induces a conformational change in the S100A6 molecule, which increases its overall hydrophobicity and allows for interaction with target proteins. ${ }^{4}$ Recently, induction of S100A6 was reported to limit the TNF- $\alpha$-induced myocyte apoptosis by associating with the tumor suppressor protein $\mathrm{p} 53 .^{5}$ S100A6 has also been implicated in many cellular processes and is often upregulated in many cancer cells. ${ }^{6}$ In addition, we previously showed that synergistic enhancement of S100A6 expression by $M L L-A F F 1$ fusion and FLT3-TKD has an important role in $M L L-A F F 1$-associated leukemogenesis. ${ }^{7}$

The present study was performed to determine whether the TNF- $\alpha$ resistance of $M L L-A F F 1$-positive ALL is mediated by inactivation of the p53 pathway by upregulation of S100A6.

\section{Materials and methods}

\section{Cell culture}

The MLL-AFF1-positive ALL cell lines SEM and RS4;11 were purchased from American Type Culture Collection (ATCC; Manassas, VA, USA). The additional MLL-AFF1-negative human-leukemia cell lines used in this study; MOLT4, Raji, H9, NAMALWA and HS-Sultan were also purchased from ATCC. The SEM cells were maintained in Dulbecco's modified Eagle's medium-high glucose (Sigma, St Louis, MO, USA) supplemented with $10 \%$ fetal bovine serum (PAN Biowest, Nuaillé, France) at $37{ }^{\circ} \mathrm{C}$ and $5 \% \mathrm{CO}_{2}$. All other cell lines were cultivated in RPMI 1640 (Sigma) supplemented with 10\% fetal bovine serum at $37{ }^{\circ} \mathrm{C}$ and $5 \% \mathrm{CO}_{2}$. These leukemia cell lines were incubated with or without TNF- $\alpha(5 \mathrm{ng} / \mathrm{ml})$ for $48 \mathrm{~h}$ before counting and collecting cells to examine the effect of TNF- $\alpha$ on leukemia cells as described previously. ${ }^{5}$ 
Cell count ratio $(\mathrm{TNF}-\alpha(+) / \mathrm{TNF}-\alpha(-))$ was calculated as cell count under TNF- $\alpha(5 \mathrm{ng} / \mathrm{ml}) /$ cell count without TNF- $\alpha$ (5 ng/ml).

\section{Western blotting analysis}

Western blotting analysis was performed as described previously. ${ }^{8}$ Equal aliquots of lysate from cell lines or homogenized mouse spleen were subjected to $10 \%$ SDS-polyacrylamide gel electrophoresis, transferred onto polyvinylidene difluoride membranes and immunoblotted with the following primary antibodies: anti-s100A6 (calcyclin; Santa Cruz Biotechnology, Santa Cruz, CA, USA), anti-p53 (Santa Cruz, Biotechnology), anti-acetyl-p53 (Millipore, Billerica, MA, USA), anti-TNF R1, anti-cleaved caspase 8 and anti-cleaved caspase 3 (Cell Signaling Technology Japan, Tokyo, Japan), or anti- $\beta$-actin (Millipore). Can Get Signal (Toyobo, Tokyo, Japan) was used to promote the reaction between primary antibody and antigen. Images were captured using a Konica SRX-201 (Konica, Tokyo, Japan). Densitometry measurements were carried out on selected scanned Western blot images, using the CS analyzer version 3 (ATTO, Tokyo, Japan). The quantified bands were normalized by $\beta$-actin expression.

\section{Small interfering RNA (siRNA) for MLL-AFF1 and S100A6}

Synthetic sense and antisense oligoribonucleotides were synthesized by Takara (Shiga, Japan). The sequences of MLL-AFF1 siRNA targeting MLL-AFF1 fusion site in SEM or RS4;11 and S100A6 siRNA targeting S100A6 were as described previously. ${ }^{7,9}$ We used the mismatch control SNC1 as a negative control siRNA (Takara). The SEM and RS4;11 were transfected with $50 \mathrm{nM}$ (final concentration) of siRNA using TransIT-TKO transfection reagent (Mirus Bio, Madison, WI, USA) according to the manufacturer's instructions. After siRNA transfection, we determined the mRNA expression of MLL/AFF1 or S100A6 by real-time quantitative PCR to confirm the silencing of mRNA expression.

\section{Real-time quantitative PCR analysis of MLL-AFF1, S100A6 and $\beta$-actin}

We determined the levels of MLL-AFF1 and S100A6 mRNA expression in leukemia cells. Total RNA was extracted and the RNAs were treated with DNase using an RNeasy Mini kit and RNase-Free DNase set (Qiagen, Germantown, MD, USA) and converted to CDNA using an RNA PCR kit (Takara). Portions of unamplified cDNA were subjected to PCR with SYBR Green PCR Core Reagents (PE Applied Biosystems, Foster City, CA, USA). Incorporation of the SYBR Green dye into the PCR products was monitored in real-time with an ABI PRISM 7700 sequence detection system (PE Applied Biosystems), thereby allowing determination of the threshold cycle at which exponential amplification of PCR products began. The threshold cycle values for cDNAs corresponding to $\beta$-actin and target genes were used to calculate the abundance of the target transcripts relative to that of $\beta$-actin mRNA. The oligonucleotide primers of MLL/AFF1 and S100A6 were as described previously. ${ }^{7,9}$

\section{Apoptosis of leukemia cell line}

To examine apoptotic events, the DeadEnd Colorimetric TUNEL System (Promega, Madison, WI, USA) was used according to the manufacturer's instructions. Apoptotic rates (\%) were calculated as follows: number of apoptotic cells relative to number of all cells.

\section{MLL-AFF1 transgenic mice}

MLL-AFF1 transgenic mice, which show lymphoma at a latest age of 12 months, at which time lymphoma cells have infiltrated the liver, lung and spleen, were established previously. ${ }^{10} \mathrm{We}$ used three $M L L-A F F 1$ transgenic mice at the age of 14 months for histopathology and western blotting analysis.

\section{Statistical analysis}

The results of the cell growth and gene expression assays were analyzed by Student's $t$-test, assuming unequal variances and two-tailed distributions. Data from all experiments represent the mean values \pm s.d. of at least triplicate samples.

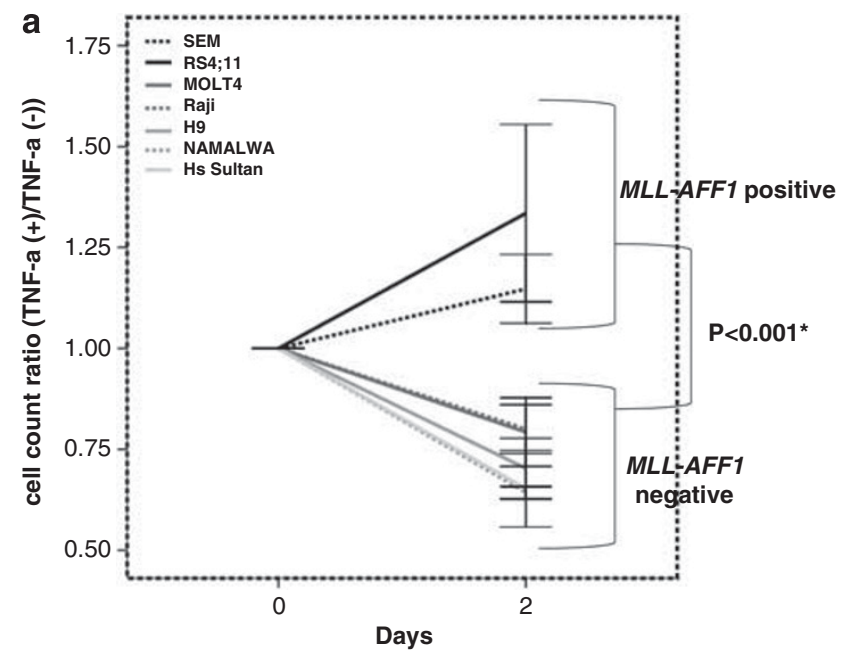

b

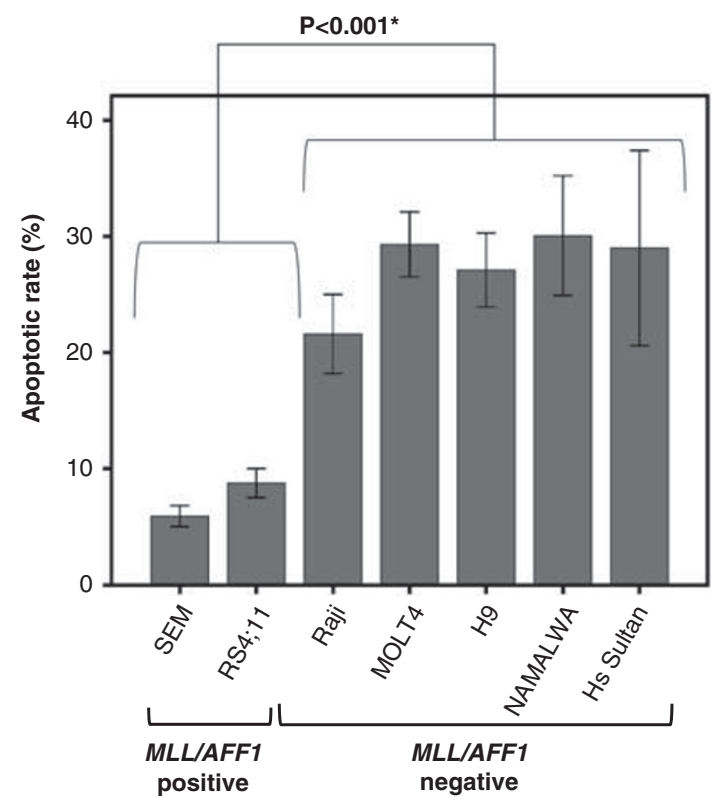

Figure 1 The comparison of sensitivity to TNF- $\alpha$ between MLL-AFF1positive ALL cell lines and MLL-AFF1-negative ALL cell lines. (a) Cell count ratio (TNF- $\alpha(+) / T N F-\alpha(-))$ of $M L L-A F F 1$-negative cell line (SEM and RS4;11) and MLL-AFF1-negative cell line (MOLT4, Raji, H9, NAMALWA, Hs Sultan). TNF- $\alpha(5 \mathrm{ng} / \mathrm{ml})$ significantly inhibited the proliferation of cell lines only in MLL-AFF1-negative cell lines $(P<0.001)$. (b) Inhibition rate by TNF- $\alpha(5 \mathrm{ng} / \mathrm{ml})$ of leukemia cell line. The apoptotic rate of $M L L-A F F 1$-positive ALL cell lines $48 \mathrm{~h}$ after addition of TNF- $\alpha(5 \mathrm{ng} / \mathrm{ml})$ were significantly lower than those of MLL-AFF1-negative leukemia cell lines. 


\section{Results}

MLL-AFF1-positive cell lines show resistance to TNF- $\alpha$ We analyzed the sensitivity to TNF- $\alpha$ of the MLL-AFF1-positive ALL cell lines SEM and RS4;11, along with the MLL-AFF1-negative leukemia cell lines MOLT4, Raji, H9, NAMALWA and HS-Sultan.

First of all, we examined the effect of TNF- $\alpha$ on proliferation of these cell lines. TNF- $\alpha(5 \mathrm{ng} / \mathrm{ml})$ significantly inhibited the proliferation of cell lines only in MLL-AFF1-negative cell lines $(P<0.001$; Figure 1a). Next, we examined the effect of TNF- $\alpha$ on apoptosis of above cell lines. The apoptotic rate of $M L L-A F F 1$ positive ALL cell lines by TNF- $\alpha(5 \mathrm{ng} / \mathrm{ml})$ were significantly lower than those of $M L L-A F F 1$-negative leukemia cell lines $(7.32 \pm 1.03 \%$ vs $27.41 \pm 1.96 \%, P<0.001$; Figure $1 \mathrm{~b})$.

S100A6 was upregulated and the p53-caspase 8-caspase 3 pathway was downregulated in $M L L-A F F 1$ positive $A L L$ cell lines in the presence of $T N F-\alpha$ We focused on S100A6 and the p53 pathway as possible factors involved in the mechanism of resistance to TNF- $\alpha$ of MLL-AFF1positive ALL cells. Western blotting analysis showed upregulation of S100A6 expression only in MLL-AFF1-positive ALL cell lines in the presence of TNF- $\alpha(5 \mathrm{ng} / \mathrm{ml}$; Figure 2$)$. Although the acetyl-p53/p53 expression ratio, the cleaved caspase 3 and the cleaved caspase 8 increased in MLL-AFF1-negative ALL cell lines in the presence of TNF- $\alpha(5 \mathrm{ng} / \mathrm{ml})$, none of them increased in $M L L-A F F 1$-positive ALL cell lines in the presence of TNF- $\alpha$ ( $5 \mathrm{ng} / \mathrm{ml}$; Figure 2). Western blotting analysis also showed there were no differences of TNF receptor 1 expression in the absence or presence of TNF- $\alpha$ (Figure 2).
MLL-AFF1 is essential for upregulation of S100A6 in the presence of TNF- $\alpha$ and S100A6 is downstream of $M L L-A F F 1$ in $M L L-A F F 1$-positive ALL cell lines

To confirm the relation between MLL-AFF1 and the upregulation of S100A6 observed in the presence of TNF- $\alpha$ in MLL-AFF1positive cell lines, we examined the expression of S100A6 mRNA and MLL-AFF1 mRNA in the MLL-AFF1-positive cell lines treated with siRNA against MLL-AFF1 or S100A6. Realtime quantitative PCR analysis showed that S100A6 mRNA expression was significantly inhibited by both MLL-AFF1 siRNA (SEM, $P=0.04$; RS4;11, $P=0.04$ ) and S100A6 siRNA (SEM, $P=0.04$; RS4;11, $P=0.02)$ in comparison with control siRNA (Figure 3a). Real-time quantitative PCR analysis also showed that $M L L-A F F 1$ mRNA expression was significantly inhibited by $M L L-A F F 1$ siRNA in comparison with control siRNA (SEM, $P=0.006$; RS4;11, $P<0.001$ ), but $M L L-A F F 1$ expression was not inhibited by S100A6 siRNA in comparison with control siRNA (SEM, $P=0.76$; RS4;11, $P=0.11$; Figure 3a). These results showed that MLL-AFF1 is essential for the upregulation of S100A6 in the presence of TNF- $\alpha$, and S100A6 is downstream of MLL/AF4 in MLL-AFF1-positive ALL cell lines.

Upregulation of S100A6 is essential for resistance of $M L L-A F F 1-p o s i t i v e ~ A L L$ cell lines to apoptosis induced by $T N F-\alpha$

To confirm the effect of S100A6 on the resistance of MLL-AFF1positive ALL cell lines to TNF- $\alpha$, we examined the apoptosis rate of $M L L-A F F 1$-positive ALL cell lines treated with siRNA against $M L L-A F F 1$ or S100A6 in the presence of TNF- $\alpha(5 \mathrm{ng} / \mathrm{ml})$. The apoptotic rate of $M L L-A F F 1$-positive ALL cell lines treated with siRNA against $M L L-A F F 1$ in the presence of TNF- $\alpha$ was

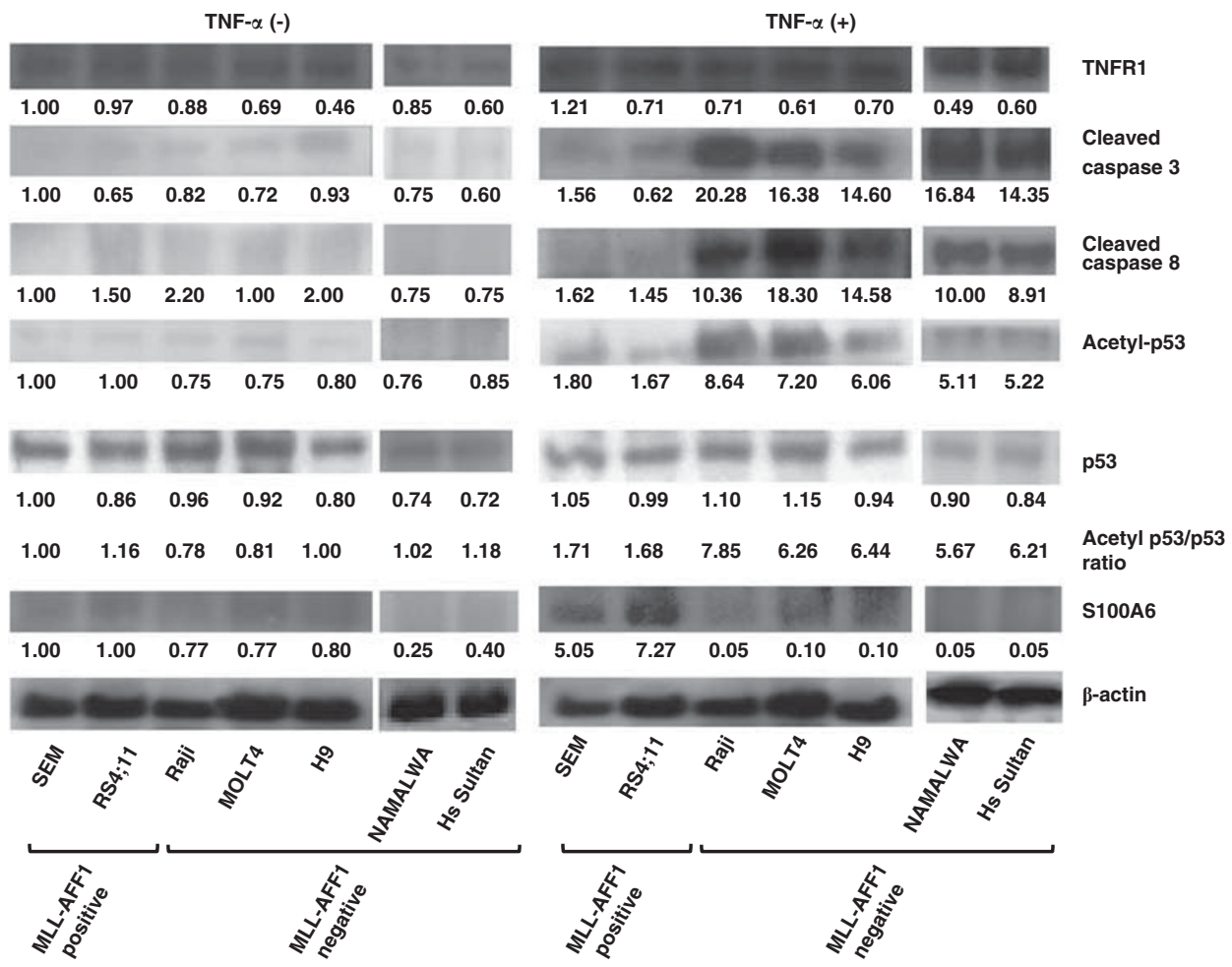

Figure 2 Western blotting analysis of lysate from leukemia cell lines. (After $48 \mathrm{~h}$ of addition or no addition of TNF- $\alpha(5 \mathrm{ng} / \mathrm{ml})$ ). All the band were quantified and normalized by $\beta$-actin. Normalized densities of SEM cells without TNF- $\alpha$ were standardized as 1.00 . Upregulation of S100A6 expression and downregulation of acetyl-p53/p53 expression ratio, cleaved caspase 3 and cleaved caspase 8 expression only in MLL-AFF1positive ALL cell lines in the presence of TNF- $\alpha(5 \mathrm{ng} / \mathrm{ml})$, although there were no significant differences between the two groups in the absence of TNF- $\alpha$. There were no differences of TNF receptor 1 (TNFR1) expression in the absence or presence of TNF- $\alpha$. Densitometry measurements were standardized by those of SEM without TNF- $\alpha$. 
a
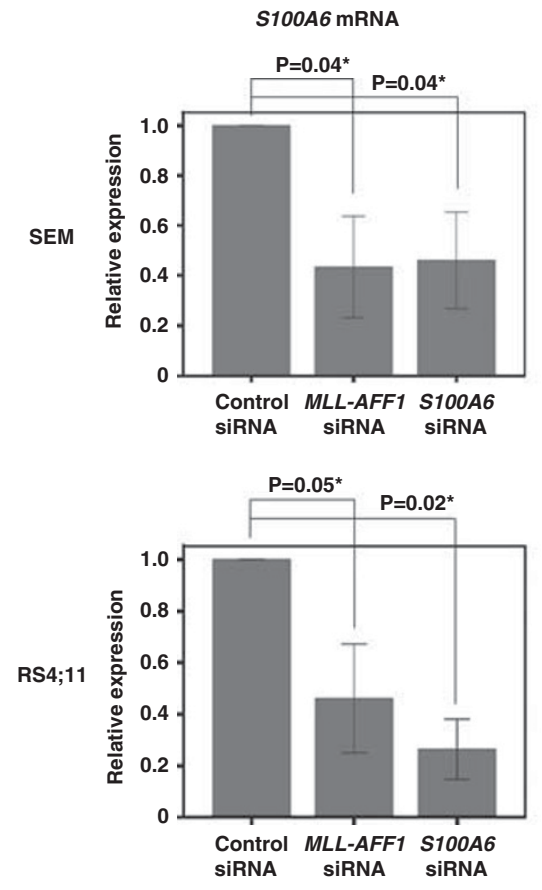

b

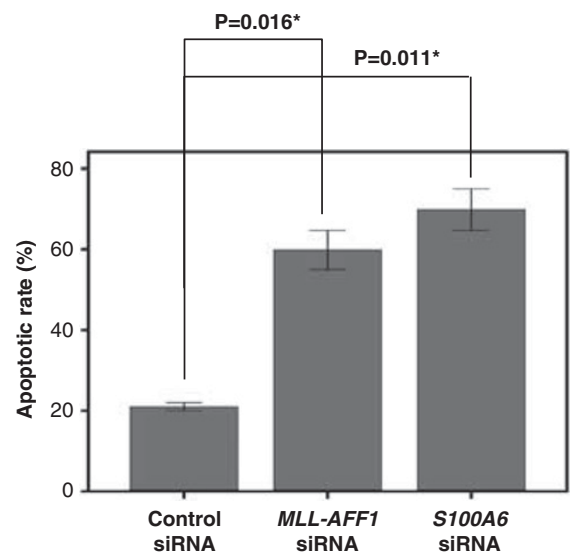

MLL-AFF1 mRNA
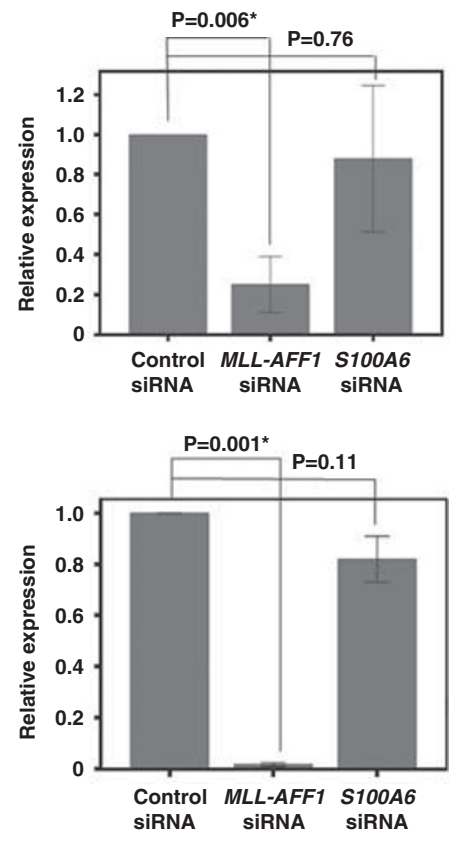

RS4;11

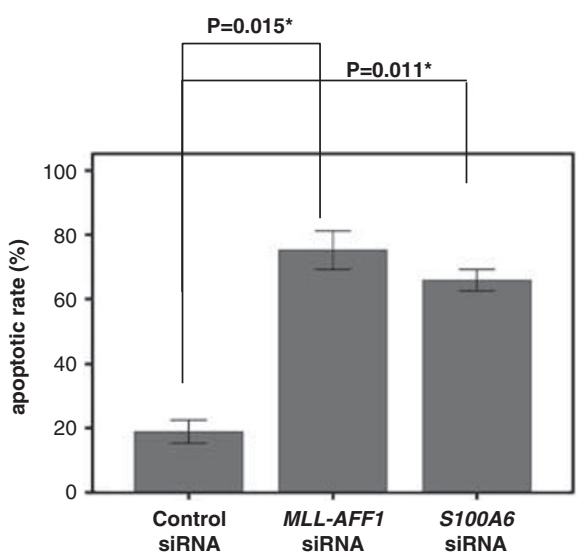

Figure 3 Effect of S100A6 siRNA or MLL-AFF1 siRNA on MLL-AFF1-positive cell lines. (a) Real-time quantitative PCR analysis of S100A6 mRNA and MLL-AFF1 mRNA under S100A6 siRNA or MLL-AFF1 siRNA or control siRNA in the presence of TNF- $\alpha$ ( $5 \mathrm{ng} / \mathrm{ml})$ of $M L L-A F F 1$-positive cell lines (SEM and RS4;11). S100A6 mRNA expression was significantly inhibited by both MLL-AFF1 siRNA and S100A6 siRNA in comparison with control siRNA. MLL-AFF1 mRNA expression was significantly inhibited by MLL-AFF1 siRNA in comparison with control siRNA, but MLL-AFF1 expression was not significantly inhibited by S100A6 siRNA. (b) Apoptotic rate by S100A6 siRNA or MLL-AFF1 siRNA or Control siRNA in the presence of TNF- $\alpha(5 \mathrm{ng} / \mathrm{ml})$ of $M L L-A F F 1$-positive cell lines (SEM and RS4;11). The apoptotic rate of MLL-AFF1-positive ALL cell lines treated with siRNA against MLL-AFF1 in the presence of TNF- $\alpha(5 \mathrm{ng} / \mathrm{ml})$ was significantly higher than those treated with control siRNA. The apoptotic rate of MLL-AFF1-positive ALL cell lines treated with siRNA against S100A6 in the presence of TNF- $\alpha$ was significantly higher than those treated with mismatch control siRNA.

significantly higher than those treated with control siRNA. (SEM, $59.85 \pm 4.85 \%$ vs $21.00 \pm 1.0 \%, \quad P=0.016 ; \quad R S 4 ; 11$, $75.20 \pm 6.00 \% 1$ vs $18.6 \pm 3.60 \%, P=0.015$; Figure $3 \mathrm{~b})$. The apoptotic rate of $M L L-A F F 1$-positive ALL cell lines treated with siRNA against S100A6 in the presence of TNF- $\alpha$ was significantly higher than those treated with mismatch control siRNA (SEM, $69.85 \pm 5.15 \%$ vs $21.00 \pm 1.00 \%, P=0.011$; RS4;11, $65.85 \pm 3.35 \%$ vs $18.60 \pm 3.60 \%, P=0.015$; Figure $3 \mathrm{~b}$ ).

Downregulation of S100A6 leads MLL-AFF1-positive ALL cell lines to apoptosis through the p53-caspase 8-caspase 3 pathway under TNF- $\alpha$

Western blotting analysis showed that all of s100A6, acetyl-p53/ p53 ratio, cleaved caspase 8 and cleaved caspase 3 expression were increased in cells treated with s100A6 siRNA in comparison with those treated with control siRNA in the presence of TNF- $\alpha$, but MLL-AFF1 expression was not inhibited by s100A6 siRNA (Figure 4). Western blotting analysis also showed that all of S100A6, acetyl-p53/p53 ratio, cleaved caspase 8 and cleaved caspase 3 expression were increased in cells treated with $M L L-A F F 1$ siRNA in comparison with those treated with control siRNA in the presence of TNF- $\alpha$ (Figure 4).

S100A6 is upregulated and the p53-caspase 8-caspase 3 pathway is downregulated in lymphoma of MLL-AFF1 transgenic mice

To examine whether S100A6 is upregulated and the p53-caspase 8-caspase 3 pathway is downregulated in vivo, 


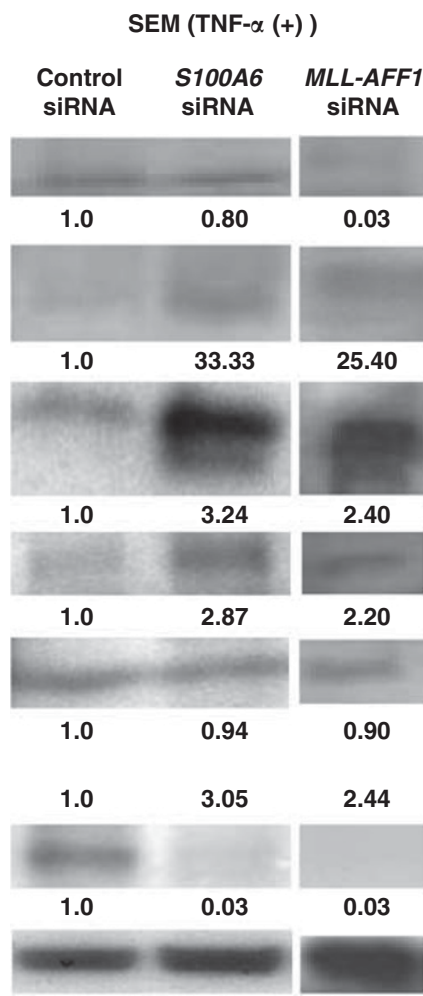

RS4;11 (TNF- $\alpha(+))$

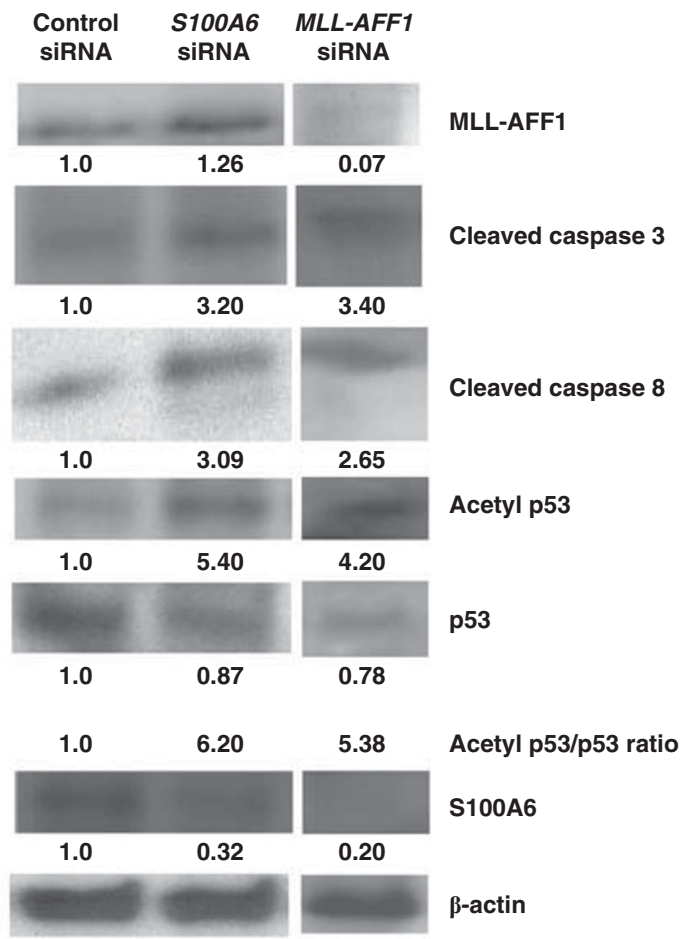

Figure 4 Western blotting analysis of lysate from MLL-AFF1-positive leukemia cell lines (SEM and RS4;11) under the MLL-AFF1 siRNA/S100A6 siRNA/control siRNA in the presence of TNF- $\alpha(5 \mathrm{ng} / \mathrm{ml})$. All of acetyl-p53/p53 ratio, cleaved caspase 8 and cleaved caspase 3 expression were increased in cells treated with MLL-AFF1 siRNA or s100A6 siRNA in comparison with those treated with control siRNA in the presence of TNF- $\alpha$ $(5 \mathrm{ng} / \mathrm{ml})$. S100A6 expression was inhibited by both MLL-AFF1 siRNA and S100A6 siRNA in comparison with control siRNA. MLL-AFF1 expression was inhibited by MLL-AFF1 siRNA in comparison with control siRNA, but MLL-AFF1 expression was not inhibited by S100A6 siRNA. Densitometry measurements of control siRNA were standardized as 1.00.

we performed western blotting analysis of the lysate from the spleens of MLL-AFF1 transgenic mice highly infiltrated by lymphoma cells (Figure 5a). Upregulation of S100A6 and downregulation of the p53-caspase 8-caspase 3 pathway were also confirmed in this mouse model (Figure $5 b$ ).

\section{Discussion}

This study showed that MLL-AFF1-positive ALL has tremendous system to escape from TNF- $\alpha$-induced apoptosis, which is a key factor of GVL effect after allo-HSCT. In MLL-AFF1-negative ALL cell lines, our results showed that TNF- $\alpha$ leads to apoptosis through caspase 8-caspase 3 pathway or p53-caspase 8-caspase 3 pathway (Figure 6a). However, our results showed that $M L L-A F F 1$-positive ALL cell lines are resistant to TNF- $\alpha$ by upregulation of S100A6 via inhibition of upregulation of the p53-caspase 8-caspase 3 pathway (Figure 6b). The resistance to GVL after allo-HSCT through this mechanism may be one of the reasons for the poor prognosis of $M L L-A F F 1$-positive ALL patients despite undergoing allo-HSCT. ${ }^{2}$

A previous study indicated that MLL fusion protein suppresses p53-mediated responses to DNA damage. ${ }^{11}$ Another study showed that $M L L$-positive leukemia is resistant to tumor necrosis factor-related apoptosis-inducing ligand (TRAIL), which has also been reported to have an important role in cytotoxic effector mechanisms, ${ }^{12-18}$ including the GVL effect. ${ }^{19}$ The downregulation of the p53-caspase 8 -caspase 3 pathway by the upregulation of S100A6 may suggest the mechanism underlying the results described in these papers.

The interaction with p53 is a common feature of S100 proteins, including S100A6. ${ }^{20-24}$ Previous studies showed that members of the $\mathrm{S} 100$ protein family bind to the tetramerization domain of p53 when it is uncovered in the monomer, and so, binding can disrupt the tetramer. ${ }^{21-28}$ Transcriptional activities of genes mediated by p53 change as a result of alterations in p53 conformation. ${ }^{21-28}$ Our results that MLL-AFF1-positive ALL cell lines are resistant to TNF- $\alpha$ by upregulation of S100A6 via inhibition of upregulation of the p53-caspase 8-caspase 3 pathway may be mediated by this interaction between S100A6 and p53. One of the emphases of this study is that we did not use severe combined immunodeficiency mice-transplantation model, but used MLL-AFF1 Tg mice model whose immune systems are basically normal. So the relations between S100A6 and p53-caspase 8-caspase 3 pathway under immune factors of mice, such as TNF- $\alpha$ could be examined in vivo model.

Interestingly, a recent study showed that S100B, which is a member of the S100 family, downregulates p53 and apoptosis in malignant melanoma. Upregulation of S100A6 in pancreatic cancer, cholangiocarcinoma, cutaneous melanoma, malignant melanoma, gastric cancer, craniopharyngioma and squamous cell carcinoma of the mouth were also reported. ${ }^{4}$ The S100 family is an attractive target of p53-mediated apoptosis of many carcinoma. On the contrary, in some carcinoma such as hepatocellular carcinoma and breast cancer, S100A6 was reported to be decreased. ${ }^{6}$ Joo et al. ${ }^{29}$ showed that S100A6 

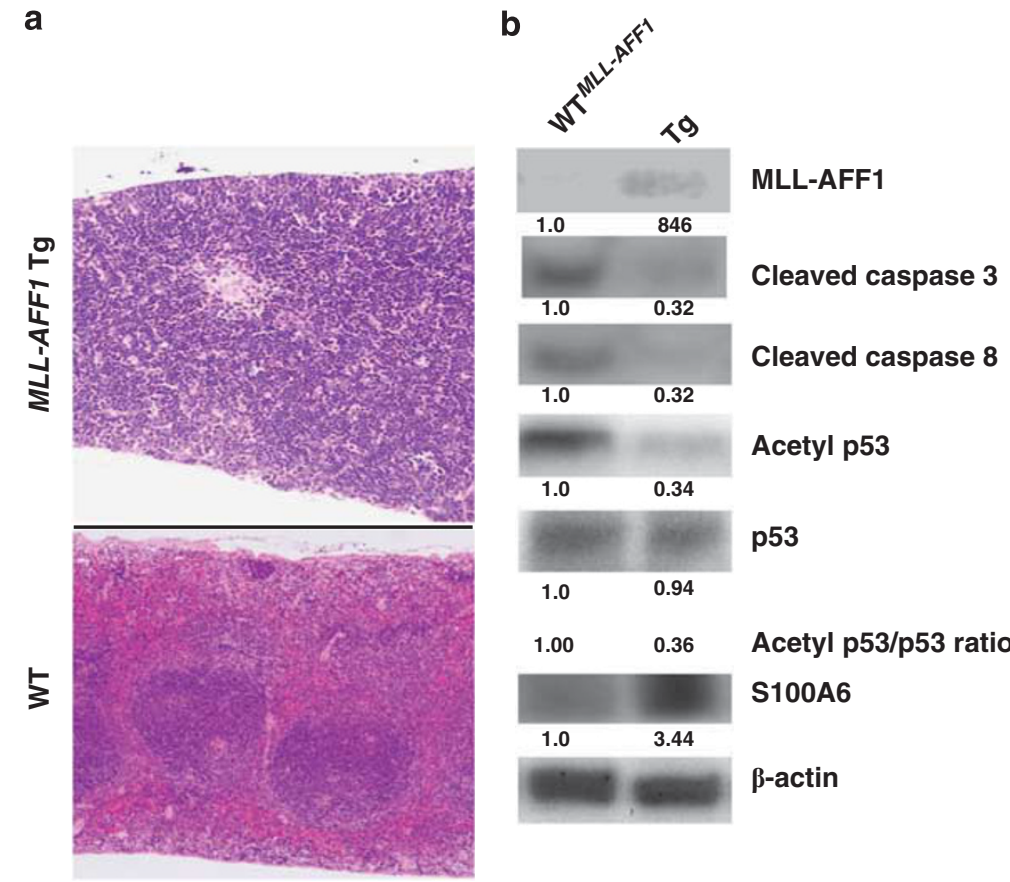

\begin{tabular}{|c|c|c|}
\hline 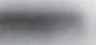 & 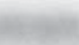 & Acetyl p53 \\
\hline \multirow[t]{2}{*}{1.0} & 0.34 & \\
\hline & & p53 \\
\hline 1.0 & 0.94 & \\
\hline \multirow[t]{2}{*}{1.00} & 0.36 & Acetyl p53/p53 ratio \\
\hline & & S100A6 \\
\hline 1.0 & 3.44 & \\
\hline & & $\beta$-actin \\
\hline
\end{tabular}

Figure 5 Examination of S100A6 expression in MLL-AFF1 transgenic (Tg) mouse. (a) Histopathological findings from 14-month-old wild-type $(\mathrm{WT})$ and MLL-AFF1 Tg mice (original magnification $\times 4$ ). Comparison of their spleens shows infiltration of lymphoma cells and destruction of the normal organ structure in the MLL-AFF1 Tg mouse. (b)Western blotting analysis of lysate from spleen of WT or MLL-AFF1 Tg mice. Upregulation of S100A6 and inhibition of upregulation of the p53-caspase 8-caspase 3 pathway were also confirmed in this mouse model. Densitometry measurements were standardized by those of WT.
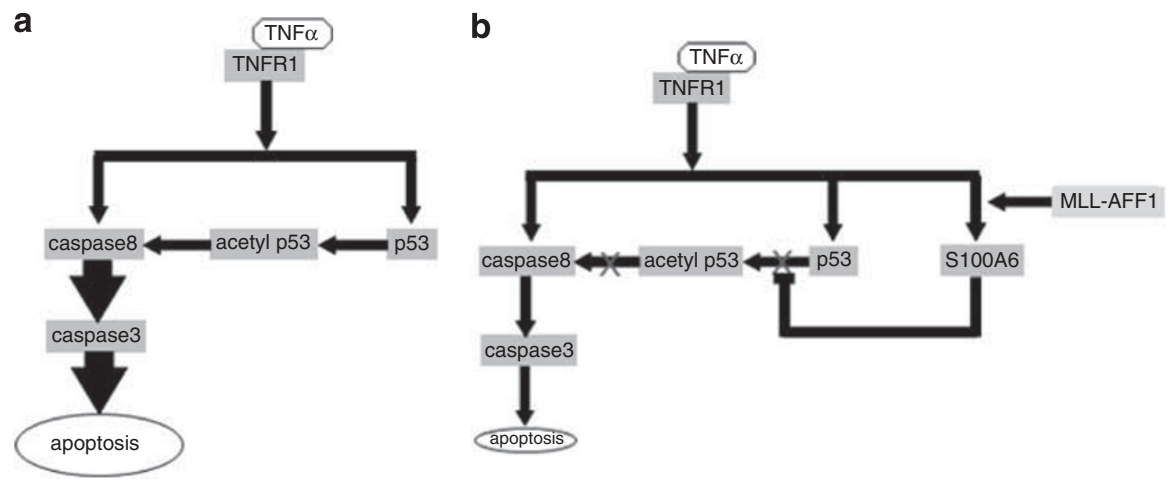

Figure 6 Working hypothesis of the effect of TNF- $\alpha$ on MLL-AFF1-positive ALL cell lines and those on MLL-AFF1-negative ALL cell lines. (a) Working hypothesis of the effect of TNF- $\alpha$ on MLL-AFF1-negative cell lines. TNF- $\alpha$ seems to lead leukemia cells to apoptosis through caspase 8-caspase 3 pathway or p53-caspase 8-caspase 3 pathway. (b) Working hypothesis of the pathway of MLL-AFF1-positive cell lines to be resistant to TNF- $\alpha$. MLL-AFF1-positive ALL cell lines seem to be resistant to TNF- $\alpha$ by upregulation of S100A6 via inhibition of upregulation of the p53-caspase 8-caspase 3 pathway.

enhances the sensitivity to apoptosis via the upregulation of caspase 3 activity in one of the hepatocellular carcinoma cell line, Нер3B, in spite of our results. This discrepancy of effect of S100A6 expression in different carcinoma may be illustrated by the model proposed by van Diecket al. ${ }^{28}$ that the binding of S100 proteins to p53 that can explain both activation and inhibition of p53-mediated transcription by alteration of the balance between monomeric p53 and tetrameric p53, depending on the concentration of $\mathrm{p} 53$ and the S100 proteins.

The incidence of MLL-AFF1-positive ALL shows a major peak in early infancy that accounts for over $50 \%$ of ALL cases in infants less than 6 months of age; $10-20 \%$ of cases occur in older infants, $2 \%$ in children, and up to $7 \%$ in adults. ${ }^{30-33}$
Although 5-year overall survival of childhood ALL patients has improved to as much as $90 \%$ due to progress in chemotherapy and other supporting therapeutic modalities, including allo$\mathrm{HSCT}^{34}$ the prognosis is still poor for the remaining $10 \%$ of the cases, which consist mainly of MLL-AFF1-positive ALL and Philadelphia chromosome-positive ALL. As use of BCR-ABL tyrosine kinase inhibitors targeting Philadelphia chromosomepositive ALL has been explored, MLL-AFF1-positive ALL is the greatest obstacle to overcoming childhood ALL.

S100A6 may be a promising therapeutic target for MLL-AFF1positive ALL in combination with allo-HSCT, because inhibition of S100A6 confers sensitivity on MLL-AFF1-positive ALL to the TNF- $\alpha$-mediated GVL effect. 


\section{Conflict of interest}

The authors declare no conflict of interest.

\section{Acknowledgements}

We thank Dr R Van Etten of Harvard Medical School for kindly providing pMSCVneop230 BCR/ABL plasmid for establishment of our MLL-AFF1 Tg mice. This work was supported in part by grants (No. 19591142) from the Ministry of Health and Welfare of Japan and the Ministry of Education, Science and Culture of Japan.

\section{References}

1 Harper DP, Aplan PD. Chromosomal rearrangements leading to MLL gene fusions: clinical and biological aspects. Cancer Res 2008; 68: 10024-10027.

2 Pui CH, Gaynon PS, Boyett JM, Chessells JM, Baruchel A, Kamps $\mathrm{W}$ et al. Outcome of treatment in childhood acute lymphoblastic leukaemia with rearrangements of the 11 q23 chromosomal region. Lancet 2002; 359: 1909-1915.

3 Ringdén O, Karlsson H, Olsson R, Omazic B, Uhlin M. The allogeneic graft-versus-cancer effect. Br J Haematol 2009; 147: 614-633.

4 Sastry M, Ketchem RR, Crescenzi O, Weber C, Lubienski MJ, Hidaka $\mathrm{H}$. The three-dimensional structure of $\mathrm{Ca}(2+)$-bound calcyclin: implications for $\mathrm{Ca}(2+)$-signal transduction by $\mathrm{S} 100$ proteins. Structure 1998; 6: 223-231.

5 Tsoporis JN, Izhar S, Parker TG. Expression of S100A6 in cardiac myocytes limits apoptosis induced by tumor necrosis factor-alpha. J Biol Chem 2008; 283: 30174-30183.

6 Leœniak W, Słomnicki ŁP, Filipek A. S100A6 - new facts and features. Biochem Biophys Res Commun 2009; 390: 1087-1092.

7 Yamaguchi $\mathrm{H}$, Hanawa $\mathrm{H}$, Uchida N, Inamai M, Sawaguchi K, Mitamura $\mathrm{Y}$ et al. Multistep pathogenesis of leukemia via the MLLAF4 chimeric gene/Flt3 gene tyrosine kinase domain (TKD) mutation-related enhancement of S100A6 expression. Exp Hemato 2009; 37: 701-714.

8 Balasubramanian N, Advani SH, Zingde SM. Protein kinase C isoforms in normal and chronic myeloid leukemic neutrophils. Distinct signal for PKC alpha by immunodetection on PVDF membrane, decreased expression of PKC alpha and increased expression of PKC delta in leukemic neutrophils. Leuk Res 1998; 22: $597-604$

9 Thomas M, Gessner A, Vornlocher HP, Hadwiger P, Greil J, Heidenreich O. Targeting MLL-AF4 with short interfering RNAs inhibits clonogenicity and engraftment of $\mathrm{t}(4 ; 11)$-positive human leukemic cells. Blood 2005; 106: 3559-3566.

10 Tamai H, Miyake K, Takatori M, Miyake N, Yamaguchi H, Dan K et al. Activated K-Ras protein accelerates human MLL/AF4induced leukemo-lymphomogenicity in a transgenic mouse model. Leukemia 2011; 25: 888-891.

11 Wiederschain D, Kawai H, Shilatifard A, Yuan ZM. Multiple mixed lineage leukemia (MLL) fusion proteins suppress p53-mediated response to DNA damage. J Biol Chem 2005; 280: 24315-24321.

12 Kägi D, Vignaux F, Ledermann B, Bürki K, Depraetere V, Nagata S et al. Fas and perforin pathways as major mechanisms of T cellmediated cytotoxicity. Science 1994; 265: 528-530.

13 Lowin B, Hahne M, Mattmann C, Tschopp J. Cytolytic T-cell cytotoxicity is mediated through perforin and Fas lytic pathways. Nature 1994; 370: 650-652.

14 Smyth MJ, Cretney E, Takeda K, Wiltrout RH, Sedger LM, Kayagaki $\mathrm{N}$ et al. Tumor necrosis factor-related apoptosis-inducing ligand (TRAIL) contributes to interferon gamma-dependent natural killer cell protection from tumor metastasis. J Exp Med 2001; 193: $661-670$

15 Takeda K, Hayakawa Y, Smyth MJ, Kayagaki N, Yamaguchi N, Kakuta $\mathrm{S}$ et al. Involvement of tumor necrosis factor-related apoptosis-inducing ligand in surveillance of tumor metastasis by liver natural killer cells. Nat Med 2001; 7: 94-100.

16 Cretney E, Takeda K, Yagita H, Glaccum M, Peschon JJ, Smyth MJ. Increased susceptibility to tumor initiation and metastasis in
TNF-related apoptosis-inducing ligand-deficient mice. J Immunol 2002; 168: 1356-1361.

17 Takeda K, Smyth MJ, Cretney E, Hayakawa Y, Kayagaki N, Yagita $\mathrm{H}$ et al. Critical role for tumor necrosis factor-related apoptosis inducing ligand in immune surveillance against tumor development. J Exp Med 2002; 195: 161-169.

18 Schmaltz C, Alpdogan O, Kappel BJ, Muriglan SJ, Rotolo JA, Ongchin $\mathrm{J}$ et al. T cells require TRAIL for optimal graft-versustumor activity. Nat Med 2002; 8: 1433-1437.

19 Inukai T, Zhang X, Goto M, Hirose K, Uno K, Akahane K et al. Resistance of infant leukemia with MLL rearrangement to tumor necrosis factor-related apoptosis-inducing ligand: a possible mechanism for poor sensitivity to antitumor immunity. Leukemia 2006; 20: 2119-2129.

20 Baudier J, Delphin C, Grunwald D, Khochbin S, Lawrence JJ. Characterization of the tumor suppressor protein p53 as a protein kinase C substrate and a S100b-binding protein. Proc Natl Acad SCi USA 1992; 89: 11627-11631.

21 Fernandez-Fernandez MR, Rutherford TJ, Fersht AR. Members of the S100 family bind p53 in two distinct ways. Protein Sci 2008; 17: 1663-1670.

22 Mueller A, Schäfer BW, Ferrari S, Weibel M, Makek M, Höchli M et al. The calcium-binding protein S100A2 interacts with p53 and modulates its transcriptional activity. J Biol Chem 2005; 280: 29186-29193.

23 Slomnicki LP, Nawrot B, Leœniak W. S100A6 binds p53 and affects its activity. Int J Biochem Cell Biol 2008; 41: 784-790.

24 Grigorian M, Andresen S, Tulchinsky E, Kriajevska M, Carlberg C, Kruse $\mathrm{C}$ et al. Tumor suppressor p53 protein is a new target for the metastasis-associated Mts1/S100A4 protein: functional consequences of their interaction. J Biol Chem 2001; 276: 22699-22708.

25 Fernandez-Fernandez MR, Veprintsev DB, Fersht AR. Proteins of the S100 family regulate the oligomerization of p53 tumor suppressor. Proc Natl Acad Sci USA 2005; 102: 4735-4740.

26 Lin J, Blake M, Tang C, Zimmer D, Rustandi RR, Weber DJ et al. Inhibition of p53 transcriptional activity by the S100B calciumbinding protein. J Biol Chem 2001; 276: 35037-35041.

27 Scotto C, Delphin C, Deloulme JC, Baudier J. Concerted regulation of wild-type p53 nuclear accumulation and activation by S100B and calcium-dependent protein kinase C. Mol Cell Biol 1999; 19: 7168-7180.

28 van Dieck J, Fernandez-Fernandez MR, Veprintsev DB, Fersht AR. Modulation of the oligomerization state of p53 by differential binding of proteins of the S100 family to p53 monomers and tetramers. J Biol Chem 2009; 284: 13804-13811.

29 Joo JH, Yoon SY, Kim JH, Paik SG, Min SR, Lim JS et al. S100A6 (calcyclin) enhances the sensitivity to apoptosis via the upregulation of caspase-3 activity in Hep3B cells. J Cell Biochem 2008; 103: $1183-1197$.

30 Pui $\mathrm{CH}$, Relling MV, Downing JR. Acute lymphoblastic leukemia. N Engl J Med 2004; 350: 1535-1548.

31 Moorman AV, Harrison CJ, Buck GA, Richards SM, Secker-Walker $\mathrm{LM}$, Martineau $\mathrm{M}$ et al. Karyotype is an independent prognostic factor in adult acute lymphoblastic leukemia (ALL): analysis of cytogenetic data from patients treated on the Medical Research Council (MRC) UKALLXII/Eastern Cooperative Oncology Group (ECOG) 2993 trial. Blood 2007; 109: 3189-3197.

32 Pui $\mathrm{CH}$, Kane JR, Crist WM. Biology and treatment of infant leukemias. Leukemia 1995; 9: 762-769.

33 Pui CH, Ribeiro RC, Campana D, Raimondi SC, Hancock ML, Behm FG et al. Prognostic factors in the acute lymphoid and myeloid leukemias of infants. Leukemia 1996; 10: 952-956.

34 Eden TO, Pieters R, Richards S. Childhood Acute Lymphoblastic Leukaemia Collaborative Group (CALLCG). Systematic review of the addition of vincristine plus steroid pulses in maintenance treatment for childhood acute lymphoblastic leukaemia - an individual patient data meta-analysis involving 5659 children. $\mathrm{Br}$ J Haematol 2010; 149: 722-733.

This work is licensed under the Creative Commons Attribution-NonCommercial-No Derivative Works 3.0 Unported License. To view a copy of this license, visit http:// creativecommons.org/licenses/by-nc-nd/3.0/ 